OPEN ACCESS

Edited by:

Fatima Baltazar,

University of Minho, Portugal

Reviewed by:

Justyna Godos,

University of Catania, Italy

Evelyn Frias-Toral,

Catholic University of Santiago de

Guayaquil, Ecuador

*Correspondence:

Hamed Mohammadi

mohamadihd@gmail.com

Specialty section:

This article was submitted to

Clinical Nutrition,

a section of the journal

Frontiers in Nutrition

Received: 25 November 2021

Accepted: 11 January 2022

Published: 10 February 2022

Citation:

Asoudeh F, Dashti F, Jayedi A,

Hemmati A, Fadel $A$ and Mohammadi H (2022) Caffeine,

Coffee, Tea and Risk of Rheumatoid

Arthritis: Systematic Review and

Dose-Response Meta-analysis of

Prospective Cohort Studies.

Front. Nutr. 9:822557.

doi: 10.3389/fnut.2022.822557

\section{Caffeine, Coffee, Tea and Risk of Rheumatoid Arthritis: Systematic Review and Dose-Response Meta-analysis of Prospective Cohort Studies}

\author{
Farzaneh Asoudeh ${ }^{1}$, Fatemeh Dashti ${ }^{1}$, Ahmad Jayedi ${ }^{2}$, Amirhossein Hemmati ${ }^{1}$, \\ Abdulmannan Fadel ${ }^{3}$ and Hamed Mohammadi ${ }^{1 *}$ \\ ${ }^{1}$ Department of Clinical Nutrition, School of Nutritional Sciences and Dietetics, Tehran University of Medical Sciences, \\ Tehran, Iran, ${ }^{2}$ Social Determinant of Health Research Center, Semnan University of Medical Sciences, Semnan, Iran, ${ }^{3}$ School \\ of Sport and Exercise Sciences, Liverpool John Moores University, Liverpool, United Kingdom
}

Objective: Prospective cohort studies on coffee, tea and caffeine in relation to the risk of rheumatoid arthritis (RA) have shown conflicting results. The aim of this study was to conduct a dose-response meta-analysis of cohort studies on the association between dietary caffeine, different types of coffee and tea consumption and the risk of RA.

Methods: PubMed/Medline, Scopus and EMBASE were searched up to July 2021 to identify relevant studies that had considered different types of coffee (caffeinated or decaffeinated), tea or caffeine exposure with RA as the main, or one of the, outcome(s). Two authors independently screened 742 publications. Finally, five prospective cohort studies were included in our meta-analysis. Pooled relative risks (RRs) were calculated by using a fixed-effects model. We also performed linear and non-linear dose-response analyses to examine the dose-response relations.

Results: Comparing extreme categories, we found a positive, significant association between coffee (RR: 1.30; 95\% Cl: 1.04-1.62; $\left.\right|^{2}=0 \%, n=5$ ) and decaffeinated coffee (RR: $1.89 ; 95 \% \mathrm{Cl}: 1.35-2.65 ; r^{2}=38.1 \%, n=3$ ) consumption and risk of RA. One additional cup of coffee consumed per day was associated with an increased risk of RA by $6 \%\left(95 \% \mathrm{Cl}: 1.02-1.10 ; R^{2}=0 \%\right)$. This increase in the risk of RA for one cup/d of decaffeinated coffee was $11 \%\left(95 \% \mathrm{Cl}: 1.05-1.18 ; l^{2}=38\right)$. No significant association was observed between caffeinated coffee, tea or caffeine intake and the risk of RA.

Conclusion: We found that a higher intake of coffee and decaffeinated coffee was associated with increased risk of RA. No significant association between caffeinated coffee, tea or caffeine intake and the risk of RA was observed.

Systematic Review Registration: https://www.crd.york.ac.uk/prospero/display_ record.php?RecordID=227665, identifier: CRD42021227665.

\footnotetext{
Keywords: rheumatoid arthritis, coffee, tea, caffeine, meta-analysis
} 


\section{INTRODUCTION}

Rheumatoid arthritis (RA) is a prevalent autoimmune disease diagnosed by joint function deterioration, erosion of cartilage and bone distraction, which can lead to daily activity dysfunction and decreased quality of life (1). This condition may increase the risk of cardiovascular disease, cancer, and respiratory complications (2). The incidence rate of RA in industrialized countries is $5-10$ per 1,000 persons (3). Patients who suffer from RA may experience symptoms including stiffness in the joints, puffy hands, weakness, fever and fatigue $(4,5)$.

The etiology of RA is not clear; nevertheless, studies have demonstrated that genetic and environmental factors are the most common determining factors in the pathogenesis of RA (6). Environmental factors such as cigarette smoking, air pollution, occupational exposure, as well as dietary factors, are aligned with RA development (7). Among dietary factors, intake of red meat and alcohol consumption are positively associated with the risk of RA $(8,9)$, while higher consumption of fruits, vegetables, fish, as well as antioxidants, are inversely associated with the risk (10). Recently, the antioxidant properties of tea and coffee and their relation to the progression of RA has been taken into consideration (11-13). Tea and coffee are rich in biologically active components including catechins, theaflavins, caffeine and chlorogenic acid (CGA), which have anti-inflammatory effects and exert protection against chronic inflammatory disease (14, 15). A recent umbrella review have demonstrated the beneficial health effects of coffee, caffeine and antioxidant properties of coffee on various health outcomes including cancers, liver health and cardiovascular disease (16). Also, in that study, no association was found between coffee as well as decaffeinated coffee consumption and risk of RA (16). Similarly, another umbrella review investigated that usual levels of tea intake reduced diverse health outcomes (17). While, in relation to RA, no association was found between tea consumption and RA (17). Overall, there are limited studies about the association between tea as well as coffee consumption and odds of RA. In this context, some of case-control studies have reported that tea consumption are related to RA development $(18,19)$. While with regards to coffee consumption, a case-control study showed higher coffee consumption was associated with greater risk of RA (20). A previous meta-analysis of two case-control and three cohort studies in 2014 (21) showed a significant association between coffee intake and the increased risk of RA in casecontrol studies, but no association was found in cohort studies. Moreover, there was no significant association for tea intake and RA incidence. The results of the previous meta-analysis were accompanied by some limitations, as they missed one study (21), and also no dose-response meta-analysis was performed. Furthermore, there was no evaluation of the type of coffee such as whether it was caffeinated or decaffeinated. Therefore, to provide updated evidence regarding the potential association of coffee and tea intake with RA risk, the present systematic review and dose-response meta-analysis of prospective cohort studies examined the association of coffee (caffeinated and decaffeinated), caffeine or tea consumption with the risk of RA in the general population.

\section{METHODS}

We reported the current meta-analysis by following the Metaanalysis of Observational Studies in Epidemiology (MOOSE) guidelines (22).

\section{Search Strategy}

The study protocol is available at https://www.crd.york.ac. uk/PROSPERO (registration number CRD 42021227665). A systematic search of available studies was performed up to July 2021 from the online databases of PubMed/Medline, EMBASE and Scopus. The following text and MeSH heading search key words were used in our search strategy: ("Arthritis, Rheumatoid" OR rheumatoid OR "rheumatoid arthritis”) AND (“Camellia sinensis") OR “Tea” OR "Coffee" OR “caffeine” OR "caffeinated"). There was no language or time restriction. We did not include published abstracts in the present systematic review and meta-analysis. More information related to search strategy are presented in Supplementary Table 1. References from included studies and previous reviews were also examined to avoid missing any publications.

\section{Inclusion and Exclusion Criteria}

The title and abstract of each study were reviewed by two independent authors (F. A and F. D) to identify potentially relevant studies. Studies with the following criteria were included: (i) all human prospective cohort studies that considered coffee, tea, caffeine or types of coffee (caffeinated or decaffeinated) as the exposure and RA as the main or one of the secondary outcomes; (ii) publications in which effect sizes were reported in the form of odds ratio, rate or risk ratios, relative risk (RRs), or hazard ratios. Letters, comments, reviews, meta-analyses, ecological studies, animal studies and studies that were conducted on children, were excluded from our systematic review and metaanalysis. The detailed information of PICOS (populations, interventions or exposures, comparators, outcomes, and study designs) for inclusion and exclusion of studies is available at Supplementary Table 2.

\section{Data Extraction}

Two independent investigators (F. A and F. D) performed the literature research and data extraction, including the name of the first author, publication year, country, age range, sex, followup duration, number of cases or cohort size, exposure type, exposure assessment method, outcome assessment, comparison categories, relevant adjusted effect sizes with 95\% confidence intervals and confounding variables adjusted for in the statistical analysis. When eligible studies reported several risk estimates, we extracted the fully adjusted effect sizes. Disagreements were resolved through discussion by third author (HM).

\section{Data Synthesis and Analysis}

We considered the RRs and their 95\% CI as the effect size for reporting the results of the present meta-analysis. The reported HRs were considered equal to RRs (23). We calculated the highest vs. lowest estimates for the main analyses. Due to the low number of studies $(n \leq 5)$, a fixed-effects metaanalysis was performed for combining study-specific results 
(24), using maximally adjusted RRs with 95\% CIs (25). The overall effect size was calculated with consideration of betweenstudy heterogeneity. Cochrane's Q-test and $I^{2}$ (26) were used as indicators of between-study heterogeneity. $I^{2}$ values $>50 \%$ were considered as significant heterogeneity among studies (26). Sensitivity analysis was conducted to find which particular study or group of studies affected the overall result by sequential exclusion of each study at a time. Publication bias was examined by visual inspection of funnel plot asymmetry and then formally assessed by Egger's asymmetry test (27) and Begg's test (28).

Linear dose-response meta-analysis was also performed to estimate the RRs per increment of one cup/d of coffee, caffeinated coffee, decaffeinated coffee and tea consumption, as well as per $200-\mathrm{mg} / \mathrm{d}$ increment of caffeine intake according to previous meta-analyses $(29,30)$, by using generalized the least squares trend estimation method $(31,32)$. Total number of subjects, number of cases or person-years and median intake for each level of the exposure were needed for the generalized least squares trend estimation method. For the studies that reported a range of coffee, caffeinated coffee, decaffeinated coffee, tea and caffeine intake, the midpoint of the upper and lower limits in each category was estimated as the corresponding dose. When the highest and lowest categories were open-ended, we assumed the length of these open-ended intervals to be equal to the adjacent intervals. To examine the potential non-linear doseresponse associations, we used random effects dose-response meta-analysis through restricted cubic splines with three knots at 10,50 , and $90 \%$ percentiles of the distribution (33). $P$-values for non-linearity were estimated by testing the null hypothesis, in which the coefficient of the second spline was equal to zero. All statistical analyses were performed using Stata software version 14 (Stata Corp, College Station, Texas, USA) and a $p$-value $<0.05$ was considered statistically significant.

\section{Quality Assessment of Studies}

The Newcastle-Ottawa Scale (NOS) was used to evaluate the quality of the included studies (34). With the NOS method, a maximum score of nine could be assigned to a study. In the present analysis, quality scores greater than six indicated high quality studies and scores of six or less indicated low-quality studies. We evaluated the overall quality of the evidence by the NutriGrade score (35). That is a tool to judge the quality of evidence presented by the meta-analysis of cohort studies and randomized controlled trials in nutrition research $(36,37)$. This score includes eight components including (1) risk of bias; (2) precision of the estimate; (3) heterogeneity; (4) directness; (5) publication bias; (6) funding bias; (7) effect size; and (8) doseresponse association. Total scores ranged from 0 to 10 . The measurement score was estimated as follows: very low ( 0 to $<4$ points), low ( 4 to $<6$ points), moderate ( 6 to $<8$ points) or high (8-10 points) certainty of the evidence.

\section{RESULTS}

\section{Findings From the Systematic Review}

Of 742 records identified, 284 studies were duplicates and 442 studies were excluded during the screening of title and abstract (Figure 1). After reading the full texts of the remaining studies, 11 studies were excluded for the following reasons: the relevant exposure of interest was not reported $(n=1)$, the study outcome was not relevant $(n=2)$, review articles $(n=2)$, and irrelevant study design $(n=6)$ (Supplementary Table 3). Finally, five prospective cohort studies (38-42) with a total of 266,985 participants were included for meta-analysis. The characteristics of the included studies are shown in Table 1. Total number of cases with RA were 1,018, varying from 69 to 480 in these studies. The studies were conducted from 2000 to 2019; three from the USA (39-41), one from Demark (42) and one from Finland (38). Age at the beginning of the studies ranged from 20 to 98 years, and the median duration of follow-up ranged from 5.3 to 19 years. In terms of exposure assessment, four studies had used food frequency questionnaires (39-42) and one study used a selfquestionnaire and interview for the exposure assessment (38). All the included studies were of high quality, based on the NOS. Quality assessment of the studies is shown in Table 1.

\section{Findings From the Meta-analysis Association Between Coffee Consumption and Risk of RA}

Five studies had examined the association between coffee intake and subsequent risk of RA (38-42). Pooled effect sizes for the highest vs. lowest category of coffee intake indicated a positive statistically significant association with risk of RA (RR: 1.30; 95\% CI: 1.04-1.62; Figure 2A). There was no statistically significant between-study heterogeneity $\left(I^{2}=0.0 \% ; P=0.61\right)$. Sensitivity analysis showed that removing each particular study at a time, did not affect the summary effects. We observed some evidence of publication bias using Begg's test $(P=0.05)$ and Egger's test $(P=0.02)$. There was a significant positive association such that an additional cup of coffee per day was correlated with a $6 \%$ increase in the risk of RA (RR: 1.06 ; 95\% CI: $1.02-$ 1.10; Figure 3A). Non-linear dose response analysis showed a positive monotonic relationship between coffee intake and risk of RA ( $\mathrm{P}_{\text {non-linearity }}=<0.01$; Figure $\left.4 \mathrm{~A}\right)$. The quality of the evidence was rated as moderate based on the NutriGrade score (Supplementary Table 4).

\section{Association Between Caffeinated Coffee Consumption and Risk of RA}

Three studies reported on the association between caffeinated coffee intake and subsequent risk of RA (39-41). Pooled effect sizes of the highest vs. lowest category of caffeinated coffee intake showed no significant association with the risk of RA (RR: 1.13 ; 95\% CI: 0.88-1.44), without evidence of betweenstudy heterogeneity $\left(I^{2}=0 \% ; P=0.62\right.$; Figure $\left.2 B\right)$. In sensitivity analysis, we found that no study affected the overall effects. Also, there was no evidence of publication bias by Begg's test $(P=0.60)$ and Egger's test $(P=0.87)$. There was no significant association between one cup of caffeinated coffee in a day and risk of RA (RR: 1.02; 95\% CI: $0.97-$ 1.06; Figure 3B). Non-linear dose response analysis showed no significant relationship between caffeinated coffee intake and risk of RA ( $\mathrm{P}_{\text {non-linearity }}=0.78$; Figure $\left.4 \mathrm{~B}\right)$. On the basis of the 


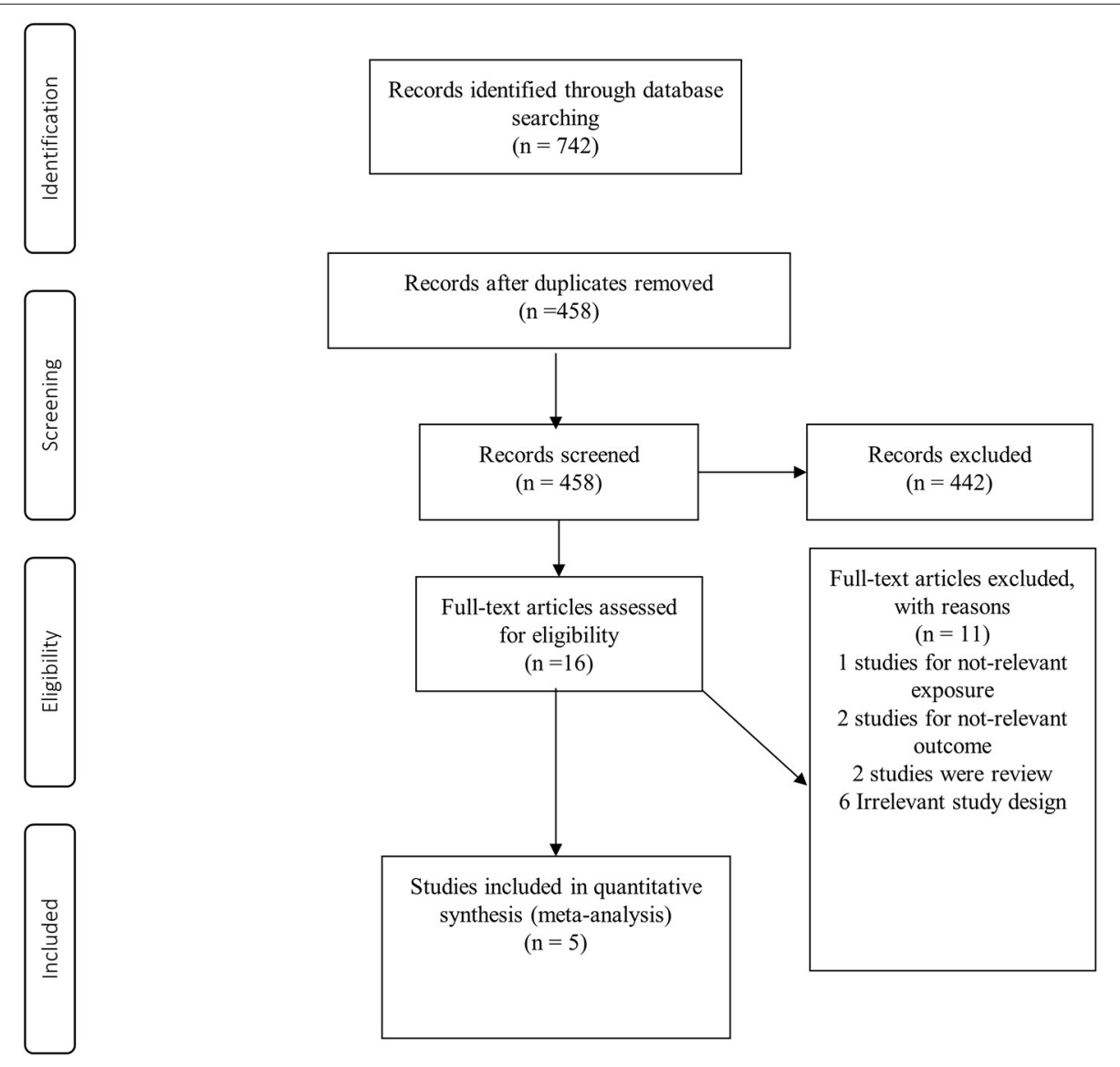

FIGURE 1 | Study selection process.

NutriGrade score, the quality of the evidence was rated as low (Supplementary Table 4).

\section{Association Between Decaffeinated Coffee Consumption and Risk of RA}

Three studies assessed the relationship between decaffeinated coffee intake and subsequent risk of RA (39-41). Pooled summary estimates for the highest vs. lowest category of decaffeinated coffee intake showed a positive association with the risk of RA (RR: 1.89; 95\% CI: 1.35-2.65; Figure 2C). We observed low evidence of between-study heterogeneity $\left(I^{2}=\right.$ $38.1 \%, P=0.19)$. Sensitivity analysis showed that removal of the study by Mikuls et al. changed the significant summary effects to non-significant (RR: 1.43 ; 95\% CI: 0.88-2.34). There was no evidence of publication bias by Begg's test $(P=0.18)$ and Egger's test $(P=0.17)$. We found a positive association between one cup of decaffeinated coffee and risk of RA. Each additional cup of decaffeinated coffee per day was associated with an $11 \%$ increased risk of RA (RR: 1.11; 95\% CI: 1.05-1.18; Figure 3C). Non-linear dose response analysis revealed a significant, positive relationship between decaffeinated coffee intake and risk of RA ( $\mathrm{P}_{\text {non-linearity }}=<0.001$; Figure $4 \mathrm{C}$ ). The quality of the evidence was rated as moderate based on the NutriGrade score (Supplementary Table 4).

\section{Association Between Caffeine Consumption and Risk of RA}

Three studies reported on the association between caffeine intake and subsequent risk of RA (39-41). Combining effect sizes for the highest vs. lowest category of caffeine intake showed no significant association with the risk of RA (RR: 1.09; 95\% CI: 0.88-1.36; Figure 2D). There was low evidence of heterogeneity among the studies $\left(I^{2}=43.2 \%\right.$; $\left.P=0.17\right)$. Sensitivity analysis indicated that exclusion of any particular study from the analysis did not alter the pooled effect sizes. No publication bias was found based on Begg's test $(P=$ $0.12)$ and Egger's test $(P=0.58)$. There was no significant association between a $200 \mathrm{mg}$ increment of caffeine intake in a day and the risk of RA (RR: 1.01; 95\% CI: 0.95-1.07; Figure 3D). Also, non-linear dose response analysis showed no significant relationship $\left(\mathrm{P}_{\text {non-linearity }}=0.77\right.$; Figure $\left.4 \mathrm{D}\right)$. Based on the NutriGrade score, the quality of the evidence was rated as low (Supplementary Table 4). 
TABLE 1 | Characteristics of included prospective cohort studies.

\begin{tabular}{|c|c|c|c|c|c|c|c|c|c|c|c|}
\hline $\begin{array}{l}\text { References, } \\
\text { country }\end{array}$ & Age, gender & $\begin{array}{l}\text { Follow } \\
\text { up }\end{array}$ & $\begin{array}{l}\text { Cases/ } \\
\text { cohort size }\end{array}$ & $\begin{array}{l}\text { Exposure } \\
\text { assessment } \\
\text { (items) }\end{array}$ & $\begin{array}{l}\text { Research } \\
\text { study }\end{array}$ & $\begin{array}{l}\text { Exposure } \\
\text { type }\end{array}$ & $\begin{array}{l}\text { Outcome } \\
\text { assessment }\end{array}$ & Contrast & $\begin{array}{l}\text { RR }(95 \% \mathrm{Cl}) \\
\text { highest versus } \\
\text { lowest }\end{array}$ & Covariates & NOS \\
\hline $\begin{array}{l}\text { Lamichhane et al. } \\
\text { (40), USA }\end{array}$ & $\begin{array}{l}50-79 \\
\text { women }\end{array}$ & $6 y$ & $185 / 76,853$ & FFQ & WHI-OS & $\begin{array}{l}\text { Coffee } \\
\text { Tea } \\
\text { Caffeine } \\
\text { Caffeinated } \\
\text { coffee } \\
\text { Decaffeinated } \\
\text { coffee }\end{array}$ & $\begin{array}{l}\text { Self-reported RA and } \\
\text { DMARD }\end{array}$ & $\begin{array}{l}\geq 4 \mathrm{cups} / \mathrm{d} \text { vs. none } \\
\geq 4 \mathrm{cups} / \mathrm{d} \text { vs. none } \\
\geq 242.96 \text { vs. } \leq 57.53 \\
\mathrm{mg} / \mathrm{d} \\
\geq 4 \mathrm{cups} / \mathrm{d} \text { vs. none } \\
\geq 4 \mathrm{cups} / \mathrm{d} \text { vs. none }\end{array}$ & $\begin{array}{l}1.29(0.84-1.98) \\
1.78(0.83-3.82) \\
1.83(1.07-3.15) \\
1.37(0.84-2.23) \\
1.76(0.92-3.36)\end{array}$ & $\begin{array}{l}\text { Age, } \\
\text { race/ethnicity, } \\
\text { marital status, } \\
\text { smoking history, } \\
\text { alcohol use, use of } \\
\text { hormone therapy, } \\
\text { education, BMl }\end{array}$ & 8 \\
\hline $\begin{array}{l}\text { Pedersen et al. } \\
\text { (42), Denmark }\end{array}$ & 50-64 both & $5.3 y$ & $69 / 56,691$ & $\mathrm{FFQ}$ & DNPR & Coffee & ACR criteria & per $200 \mathrm{~g} / \mathrm{d}$ & $1.10(0.99-1.21)$ & $\begin{array}{l}\text { Age, gender, } \\
\text { tobacco smoking, } \\
\text { education }\end{array}$ & 8 \\
\hline $\begin{array}{l}\text { Mikuls et al. (41), } \\
\text { USA }\end{array}$ & 55-69 women & $12 \mathrm{y}$ & 158/31,336 & FFQ (127) & IWHS & $\begin{array}{l}\text { Coffee } \\
\text { Tea } \\
\text { Caffeine } \\
\text { Caffeinated } \\
\text { coffee } \\
\text { Decaffeinated } \\
\text { coffee }\end{array}$ & ACR criteria & $\begin{array}{l}\geq 4 \text { cups/d vs. none } \\
>3 \text { cups/d vs. none } \\
>376.5 \text { vs. }<29.1 \\
\text { mg/d } \\
\geq 4 \text { cups/d vs. none } \\
\geq 4 \text { cups/d v.s none }\end{array}$ & $\begin{array}{l}1.56(0.80-3.06) \\
0.35(0.13-0.97) \\
0.94(0.58-1.52) \\
0.98(0.60-1.61) \\
2.44(1.52-3.89)\end{array}$ & $\begin{array}{l}\text { Age, marital } \\
\text { status, smoking } \\
\text { history, alcohol } \\
\text { use, age at } \\
\text { menopause, and } \\
\text { use of hormone } \\
\text { replacement } \\
\text { therapy }\end{array}$ & 8 \\
\hline $\begin{array}{l}\text { Karlson et al. (39), } \\
\text { USA }\end{array}$ & $\begin{array}{l}34-59 \\
\text { women }\end{array}$ & $19 y$ & $480 / 83,124$ & FFQ & NHS & $\begin{array}{l}\text { Coffee } \\
\text { Tea } \\
\text { Caffeine } \\
\text { Caffeinated } \\
\text { coffee } \\
\text { Decaffeinated } \\
\text { coffee }\end{array}$ & ACR criteria & $\begin{array}{l}\geq 4 \text { vs. } 0 \text { cups } / \mathrm{d} \\
>3 \text { vs. } 0 \text { cups } / \mathrm{d} \\
>700 \text { vs. }<142 \mathrm{mg} / \mathrm{d} \\
\geq 4 \text { vs. } 0 \text { cups } / \mathrm{d} \\
\geq 4 \text { vs. } 0 \text { cups } / \mathrm{d}\end{array}$ & $\begin{array}{c}1.2(0.9-1.7) \\
(0.7-1.8) \\
(0.8-1.4) \\
(0.8-1.6) \\
1.1(0.5-2.2)\end{array}$ & $\begin{array}{l}\text { Age, alcohol use, } \\
\text { smoking, BMI, age } \\
\text { at menarche, age } \\
\text { at first birth, parity, } \\
\text { breastfeeding, oral } \\
\text { contraceptive use, } \\
\text { use of hormone } \\
\text { replacement } \\
\text { therapy }\end{array}$ & 6 \\
\hline $\begin{array}{l}\text { Heliövaara et al. } \\
\text { (38), Finland }\end{array}$ & 20-98 both & $17 \mathrm{y}$ & $126 / 18,981$ & $\begin{array}{l}\text { Self- } \\
\text { questionnaire } \\
\text { and interview }\end{array}$ & MCHES & Coffee & $\begin{array}{l}\text { Record linkage } \\
\text { Medical record }\end{array}$ & 10 vs. 0 cups/d & $3.95(0.89-17.51)$ & Age, sex & 9 \\
\hline
\end{tabular}

FFQ, food frequency questionnaire; RA, rheumatoid arthritis; DMARD, disease-modifying anti-rheumatic drugs; BMI, body mass index; ACR, American College of Rheumatology; NOS, Newcastle-Ottawa Scale; WHI-OS, Women's Health Initiative Observational Study; DNPR, Danish National Patient Registry; IWHS, lowa Women's Health; NHS, Nurses' Health Study; MCHES, Mobile Clinic Health Examination Survey Study. 


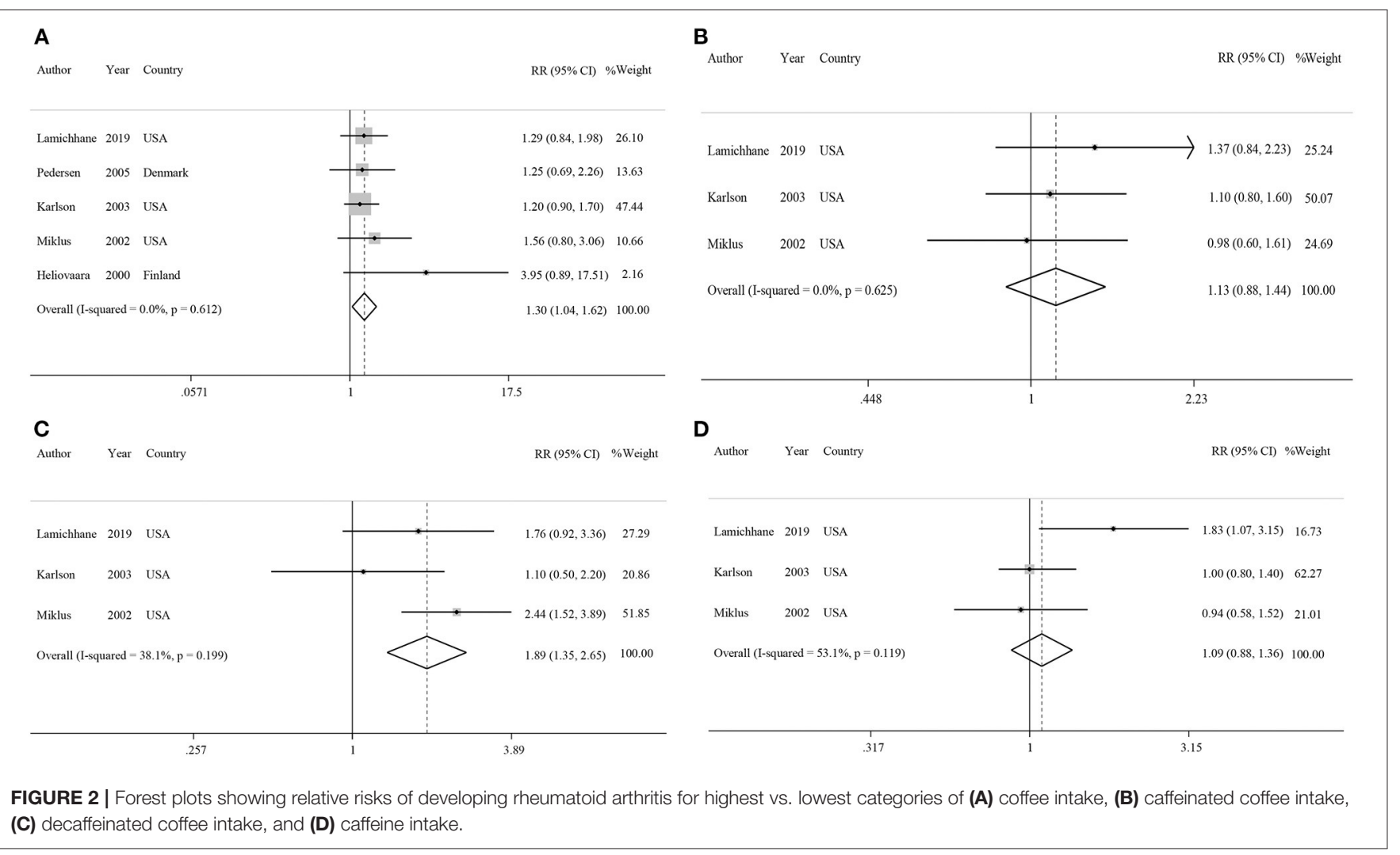

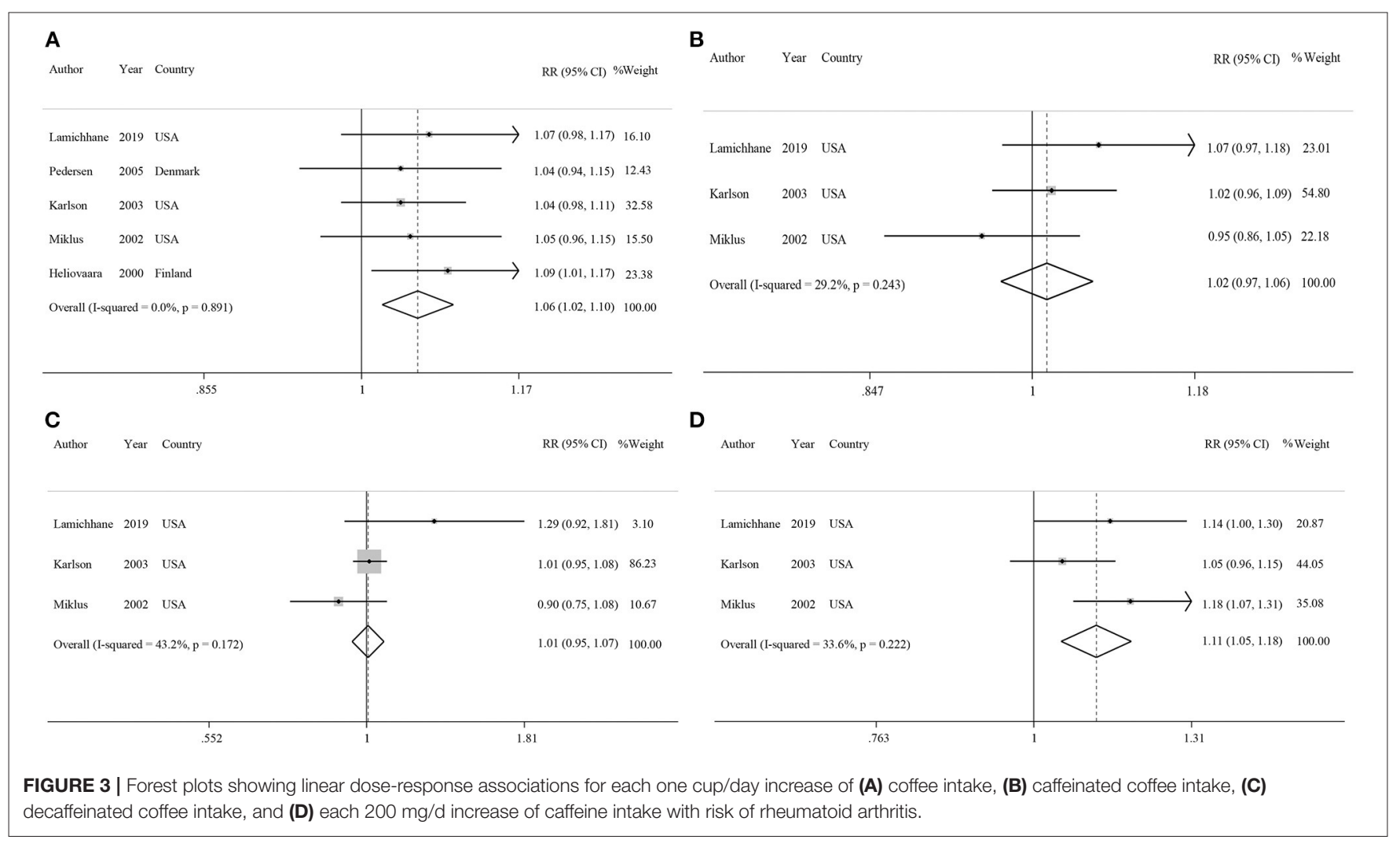



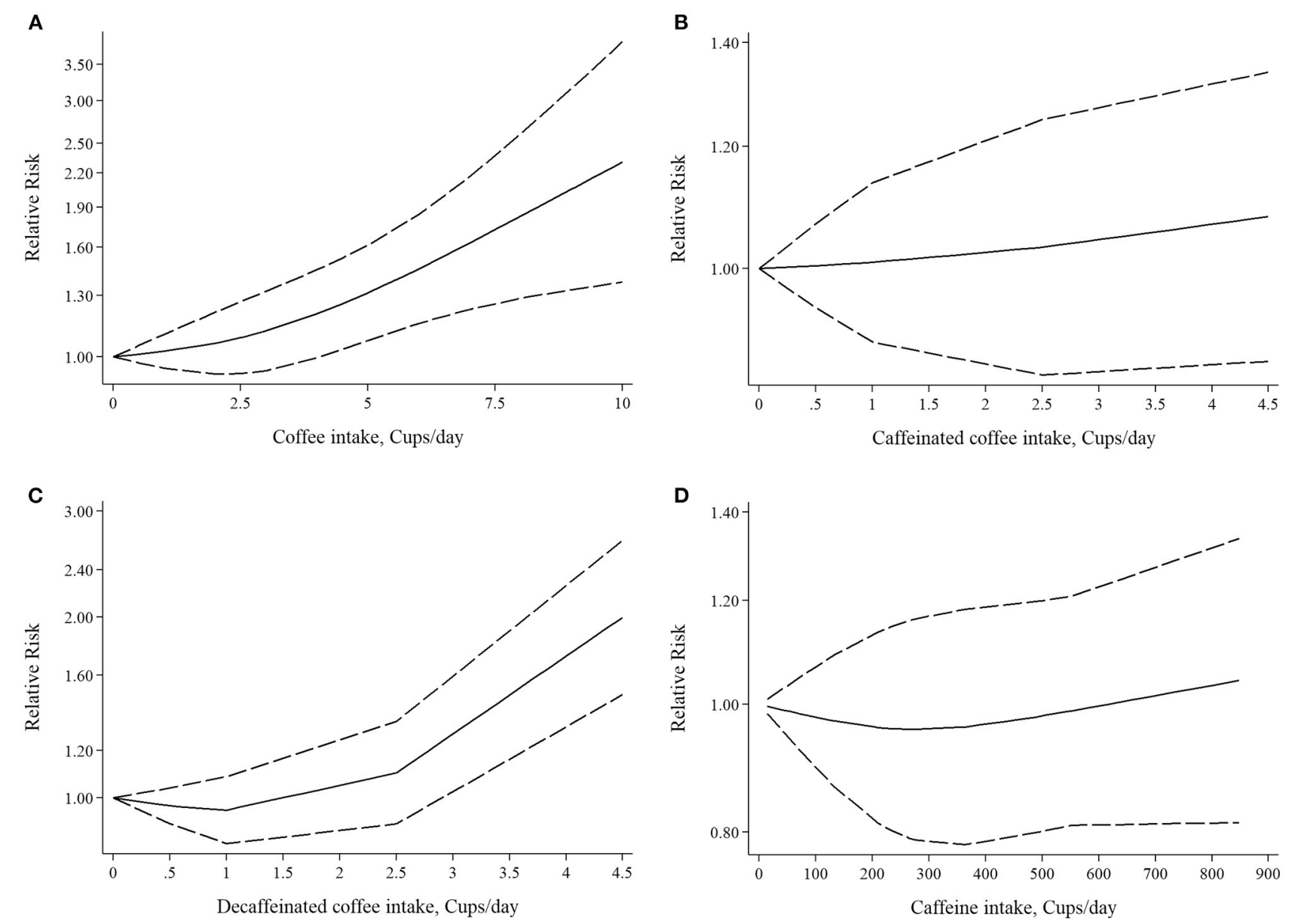

FIGURE 4 | Nonlinear dose-response associations of (A) coffee intake, (B) caffeinated coffee intake, (C) decaffeinated coffee intake, (D) caffeine intake and risk of rheumatoid arthritis.

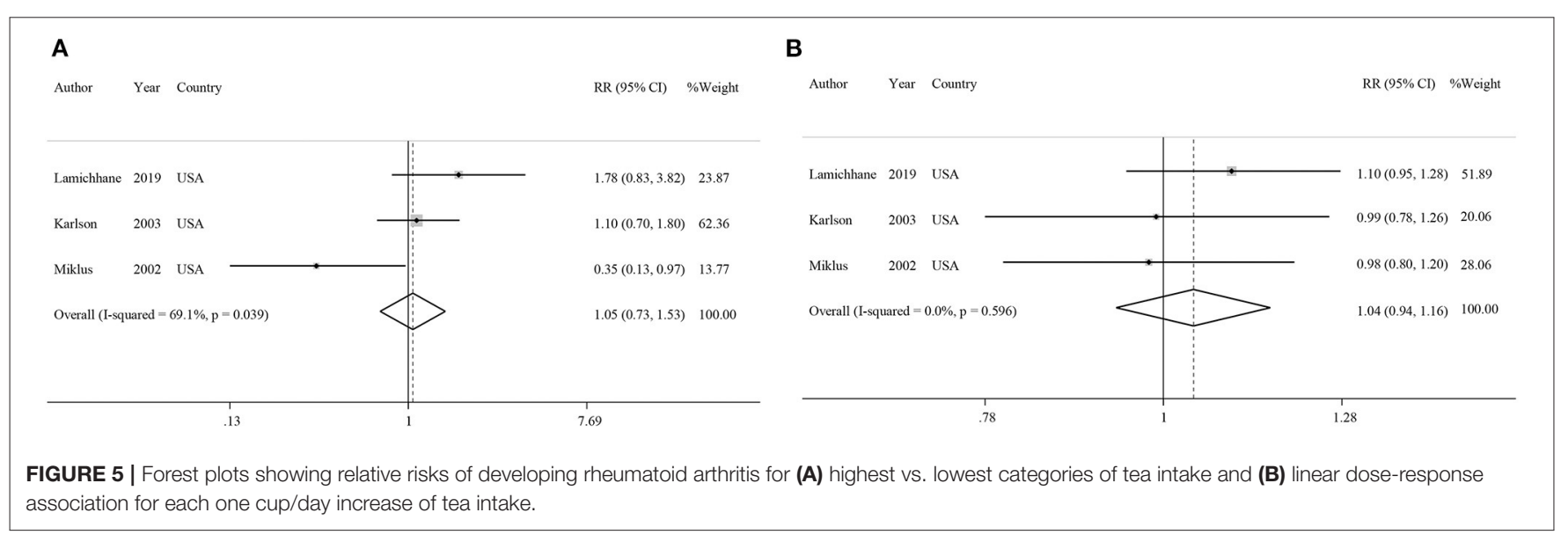

\section{Association Between Tea Consumption and Risk of \\ RA}

Three studies had examined the association between tea intake and risk of RA (39-41). Pooled effect sizes for the highest vs. lowest category of tea intake showed no significant association between tea intake and risk of RA (RR: 1.05; 95\% CI: 0.73-1.53; Figure 5A), with significant heterogeneity among the studies $\left(I^{2}\right.$ $=69.1 \% ; P=0.03)$. Furthermore, sensitivity analysis found that 
the overall effect size did not depend on a single study. There was no evidence of publication bias by Begg's test $(P=0.60)$ and Egger's test $(P=0.70)$. There was no statistically significant association between one cup of tea per day and risk of RA (RR: 1.04; 95\% CI: 0.94-1.16; Figure 5B). Also, non-linear doseresponse analysis did not reveal any association $\left(\mathrm{P}_{\text {non-linearity }}=\right.$ 0.61 ; Figure 6). Using the NutriGrade score, the quality of the evidence was found to be low (Supplementary Table 4).

\section{DISCUSSION}

RA is a chronic autoimmune inflammatory disease that leads to inflammation and joint pain that might affect other organs. Dietary components can affect the severity or improvement of the disease symptoms. Numerous studies have shown that coffee and tea consumption could increase inflammatory markers in these patients $(20,38,41)$. On the other hand, a number of other studies have revealed the protective role of coffee and tea in RA $(18,19)$. As a result, we conducted a systematic review and meta-analysis on relevant cohorts to summarize the findings of these studies. The results of our systematic review and meta-analysis of five cohort studies showed a significant association between coffee intake and the risk of RA. We found a similar positive association between decaffeinated coffee intake and the risk of RA. We did not observe significant associations between caffeine, caffeinated coffee and tea intake with the risk of RA.

In the present study, we found that higher coffee intake was associated with an increased risk of RA, which is consistent with the case-control study by Pedersen et al. who found a significant, positive association between coffee intake and the risk of RA (20). The possible mechanism by which coffee may associated with the increased risk of RA is related to the effect of coffee on the level of inflammatory markers. Zampelas et al., in a cohort study, found that IL-6 increased among those drinking more than four cups per day (28). However, there are studies that report conflicting results. Some studies have shown that coffee can exert antiinflammatory and antioxidant effects due to compounds such as caffeine, cafestol, chlorogenic acid and trigonelline (43). This theory has been supported in some observational studies. The Nurses' Health Study II showed a negative association between coffee consumption and c-reactive protein, interleukin-6, tumor necrosis factor alpha and other inflammatory markers (44).

Another mechanism for significant association between coffee intake and an increased risk of RA may be the lack of controlling for confounding variables such as physical activity, smoking, and other lifestyle-related factors. Studies have shown that people who consume higher amounts of coffee are more likely to be a smoker $(45,46)$. Smoking is a risk factor for increased levels of inflammation and diseases such as RA (47). Our findings revealed that increased caffeine consumption was not related to an increase in risk of RA. Thus, besides caffeine, other chemical ingredients that are used in the growing or preparation of coffee may be responsible for this finding.

With regards to caffeinated coffee, we found no significant association between its intake and the risk of RA. Some studies have demonstrated that people who drank caffeinated coffee had

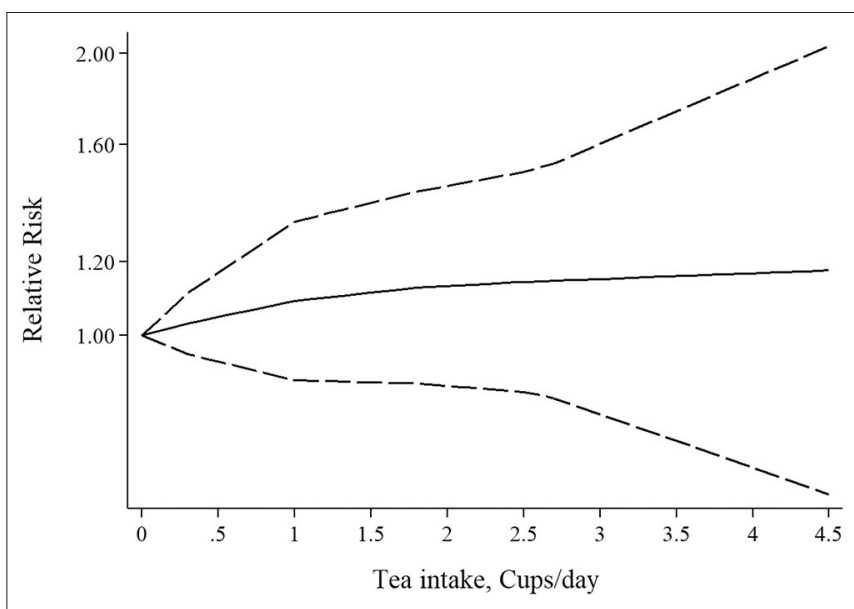

FIGURE 6 | Non-linear dose-response association of tea intake and risk of rheumatoid arthritis.

higher levels of IL-6 compared to those consuming no coffee $(48,49)$. On the other hand, Wedick et al., in a clinical trial, have shown that caffeinated coffee can increase adiponectin levels (49). Some studies have pointed out that adiponectin can play a proinflammatory role in the pathophysiology of autoimmune disease such as RA through stimulating the secretion of inflammatory mediators $(50,51)$.

We also found a positive association between decaffeinated coffee consumption and the risk of RA. The mechanism involved seems to be the method of extracting caffeine from coffee by direct application of industrial solvents including benzene, acetone, ammonium hydroxide, sulfuric acid, ethyl acetate, methylene chloride, chloroform, ether, alcohol, trichloroethylene and carbon tetrachloride (52). Chronic ingestion of solvent residues, even small quantities, could result in connective tissue disorders such as scleroderma, lupus, and RA (53). Additionally, decaffeinated coffee has a smaller even higher antioxidant activity than regular coffee $(54,55)$.

In our study, there was no significant relationship between tea consumption and the risk of RA. However, a case-control study in Iran showed an inverse association between tea consumption and the risk of RA (18). Similarly, Jin et al., in a cross-sectional study on RA patients, found an inverse association between high tea consumption $(>750 \mathrm{~mL} /$ day $)$ and disease severity in patients with RA (56). A number of studies have also shown that tea consumption could have a beneficial effect on inflammatory factors which is due to catechins and other flavonoids $(57,58)$. The null findings observed in our study may be due to the insufficient prospective cohort studies examining the association between tea intake and the incidence of inflammation and RA. Also, the included studies did not report the risk of RA according to the type of tea. Although the exact role of different types of tea in the pathogenesis of RA remains unknown, some publications have indicated that green tea has an immunomodulatory effect and, thus, can protect against RA (59). Furthermore, Rambod et al., in a case-control study, showed that green tea intake was 
correlated with a $35 \%$ decreased risk of RA (19). On the other hand, there are studies that have indicated that black tea intake was not associated with the level of inflammatory markers (6062). Given that all types of tea are processed differently, this may lead to changes in chemical ingredients and finally different properties (40).

We did not observe a significant relationship between caffeine intake and the risk of RA. Our finding is in agreement with a previous systematic review on clinical trials indicating that caffeine has no definite role in short-term inflammatory responses and these pathways are not clearly understood (63). However, a cross-sectional study found a statistically significant reduction in disease activity and cytokine levels in systemic lupus erythematosus patients who had higher intakes of caffeine (64). It was shown that caffeine metabolites, such as xanthine and theobromine, have antioxidant activities and decrease hydroxyl radicals (65). Also, it is believed that caffeine has an adenosine antagonist effect and can induce a decrease in cytokine production (66).

The present study has some strengths that should be acknowledged. Unlike previous meta-analyses, we performed a dose-response analysis which has provided more precise results than the highest vs. lowest analysis. Also, we assessed the association of different types of coffee (caffeinated vs. decaffeinated) with RA which revealed their different effects on RA. Moreover, the included studies were a cohort with a relatively large sample size which increased the generalizability of the findings and statistical inferences.

In spite of these strengths, this study has some limitations which should be taken into account when interpreting the results. First, our study included a small number of publications that weakened the interpretation of the relationships in the metaanalyses. Second, the results are subject to residual confounding because of the cohort design of the included studies. Third, most of the included studies used a food frequency questionnaire to evaluate dietary intake and, therefore, measurement error and

\section{REFERENCES}

1. Scott DL, Wolfe F, Huizinga TW. Rheumatoid arthritis. Lancet. (2010) 376:1094-8. doi: 10.1016/S0140-6736(10)60826-4

2. England BR, Thiele GM, Anderson DR, Mikuls TR. Increased cardiovascular risk in rheumatoid arthritis: mechanisms and implications. BMJ. (2018) 361:k1036. doi: 10.1136/bmj.k1036

3. Essouma M, Nkeck JR, Endomba FT, Bigna JJ, Ralandison S. Epidemiology of rheumatoid arthritis in sub-Saharan Africa: a systematic review and meta-analysis protocol. Syst Rev. (2020) 9:1-4. doi: 10.1186/s13643-02001342-5

4. Rindfleisch AJ, Muller D. Diagnosis and management of rheumatoid arthritis. Am Fam Phys. (2005) 72:1037-47.

5. Walsh DA, McWilliams DF. Mechanisms, impact and management of pain in rheumatoid arthritis. Nat Rev Rheumatol. (2014) 10:58192. doi: 10.1038/nrrheum.2014.64

6. McInnes IB, Schett G. The pathogenesis of rheumatoid arthritis. New Engl J Med. (2011) 365:2205-19. doi: 10.1056/NEJMra1004965

7. Hoovestol RA, Mikuls TR. Environmental exposures and rheumatoid arthritis risk. Curr Rheumatol Rep. (2011) 13:431. doi: 10.1007/s11926-0110203-9 misclassification of the study participants in terms of exposure were inevitable. Finally, the size of the cup of coffee and tea in the entire study was not determined, which could influence the observed associations.

\section{CONCLUSION}

Subject to the limitations such as low number of studies and weak statistical power, we observed a positive association between coffee, decaffeinated coffee intake and the risk of RA. However, no statistically significant associations were observed between caffeinated coffee, caffeine or tea consumption with the incidence of RA. More experimental and observational studies are needed to substantiate such findings.

\section{DATA AVAILABILITY STATEMENT}

The original contributions presented in the study are included in the article/Supplementary Materials, further inquiries can be directed to the corresponding author.

\section{AUTHOR CONTRIBUTIONS}

FA, FD, and AH contributed to the conception, design literature search, and manuscript drafting. AJ and AF contributed to the design, statistical analyses, and interpretation of data. HM contributed to the conception, design, data interpretation, drafting of the manuscript, and supervised the study. Final manuscript was approved by all authors approved prior to submission.

\section{SUPPLEMENTARY MATERIAL}

The Supplementary Material for this article can be found online at: https://www.frontiersin.org/articles/10.3389/fnut.2022. 822557/full\#supplementary-material
8. VanEvery H, Yang W, Olsen N, Bao L, Lu B, Wu S, et al. Alcohol consumption and risk of rheumatoid arthritis among Chinese adults: a prospective study. Nutrients. (2021) 13:2231. doi: 10.3390/nu13072231

9. Philippou E, Nikiphorou E. Are we really what we eat? Nutrition and its role in the onset of rheumatoid arthritis. Autoimmun Rev. (2018) 17:10747. doi: 10.1016/j.autrev.2018.05.009

10. Skoczyńska M, Swierkot J. The role of diet in rheumatoid arthritis. Reumatologia. (2018) 56:259-67. doi: 10.5114/reum.2018.77979

11. Serafini M, Ghiselli A, Ferro-Luzzi A. In vivo antioxidant effect of green and black tea in man. Eur J Clin Nutr. (1996) 50:28-32.

12. Natella F, Nardini M, Giannetti I, Dattilo C, Scaccini C. Coffee drinking influences plasma antioxidant capacity in humans. J Agric Food Chem. (2002) 50:6211-6. doi: 10.1021/jf025768c

13. Dey M, Cutolo M, Nikiphorou E. Beverages in rheumatoid arthritis: what to prefer or to avoid. Nutrients. (2020) 12:3155. doi: 10.3390/nu12103155

14. de Mejia EG, Ramirez-Mares MV, Puangpraphant S. Bioactive components of tea: cancer, inflammation and behavior. Brain Behav Immun. (2009) 23:72131. doi: 10.1016/j.bbi.2009.02.013

15. Tajik N, Tajik M, Mack I, Enck P. The potential effects of chlorogenic acid, the main phenolic components in coffee, on health: a comprehensive review of the literature. Eur J Nutr. (2017) 56:2215-44. doi: 10.1007/s00394-017-1379-1 
16. Grosso G, Godos J, Galvano F, Giovannucci EL. Coffee, caffeine, and health outcomes: an umbrella review. Annu Rev Nutr. (2017) 37:13156. doi: 10.1146/annurev-nutr-071816-064941

17. Yi M, Wu X, Zhuang W, Xia L, Chen Y, Zhao R, et al. Tea consumption and health outcomes: umbrella review of meta-analyses of observational studies in humans. Mol Nutr Food Res. (2019) 63:1900389. doi: 10.1002/mnfr.201900389

18. Mosalmanzadeh N, Jandari S, Soleimani D, Shadmand Foumani Moghadam MR, Khorramrouz F, Araste A, et al. Major dietary patterns and food groups in relation to rheumatoid arthritis in newly diagnosed patients. Food Sci Nutr. (2020) 8:6477-86. doi: 10.1002/fsn3.1938

19. Rambod M, Nazarinia M, Raieskarimian F. The impact of dietary habits on the pathogenesis of rheumatoid arthritis: a case-control study. Clin Rheumatol. (2018) 37:2643-8. doi: 10.1007/s10067-018-4151-x

20. Pedersen M, Jacobsen S, Klarlund M, Pedersen BV, Wiik A, Wohlfahrt J, et al. Environmental risk factors differ between rheumatoid arthritis with and without auto-antibodies against cyclic citrullinated peptides. Arthritis Res Ther. (2006) 8:R133. doi: 10.1186/ar2022

21. Lee YH, Bae S-C, Song GG. Coffee or tea consumption and the risk of rheumatoid arthritis: a meta-analysis. Clin Rheumatol. (2014) 33:157583. doi: 10.1007/s10067-014-2631-1

22. Stroup DF, Berlin JA, Morton SC, Olkin I, Williamson GD, Rennie D, et al. Meta-analysis of observational studies in epidemiology: a proposal for reporting. JAMA. (2000) 283:2008-12. doi: 10.1001/jama.283.15.2008

23. Symons M, Moore D. Hazard rate ratio and prospective epidemiological studies. J Clin Epidemiol. (2002) 55:8939. doi: 10.1016/S0895-4356(02)00443-2

24. Borenstein M, Hedges LV, Higgins JP, Rothstein HR. Introduction to Metaanalysis. Pondicherry: John Wiley \& Sons (2011).

25. Jackson D, Riley R, White IR. Multivariate meta-analysis: potential and promise. Stat Med. (2011) 30:2481-98. doi: 10.1002/sim.4172

26. Higgins JP, Thompson SG, Deeks JJ, Altman DG. Measuring inconsistency in meta-analyses. BMJ. (2003) 327:557-60. doi: 10.1136/bmj.327.7414.557

27. Egger M, Davey Smith G, Schneider M, Minder C. Bias in metaanalysis detected by a simple, graphical test. BMJ. (1997) 315:62934. doi: 10.1136/bmj.315.7109.629

28. Begg CB, Mazumdar M. Operating characteristics of a rank correlation test for publication bias. Biometrics. (1994) 50:1088-101. doi: 10.2307/2533446

29. Shah SA, Chu BW, Lacey CS, Riddock IC, Lee M, Dargush AE. Impact of acute energy drink consumption on blood pressure parameters: a meta-analysis. Ann Pharmacother. (2016) 50:808-15. doi: 10.1177/1060028016656433

30. Qi H, Li S. Dose-response meta-analysis on coffee, tea and caffeine consumption with risk of Parkinson's disease. Geriatr Gerontol Int. (2014) 14:430-9. doi: 10.1111/ggi.12123

31. Orsini N, Bellocco R, Greenland S. Generalized least squares for trend estimation of summarized dose-response data. Stata J. (2006) 6:4057. doi: 10.1177/1536867X0600600103

32. Berlin JA, Longnecker MP, Greenland S. Meta-analysis of epidemiologic dose-response data. Epidemiology. (1993) 4:21828. doi: 10.1097/00001648-199305000-00005

33. Harrell FE Jr., Lee KL, Pollock BG. Regression models in clinical studies: determining relationships between predictors and response. J Natl Cancer Inst. (1988) 80:1198-202. doi: 10.1093/jnci/80.15.1198

34. Stang A. Critical evaluation of the Newcastle-Ottawa scale for the assessment of the quality of nonrandomized studies in meta-analyses. Eur J Epidemiol. (2010) 25:603-5.

35. Schwingshackl L, Knüppel S, Schwedhelm C, Hoffmann G, Missbach B, Stelmach-Mardas M, et al. Perspective: NutriGrade: a scoring system to assess and judge the meta-evidence of randomized controlled trials and cohort studies in nutrition research. Adv Nutr. (2016) 7:9941004. doi: 10.3945/an.116.013052

36. Galbete C, Schwingshackl L, Schwedhelm C, Boeing H, Schulze MB. Evaluating mediterranean diet and risk of chronic disease in cohort studies: an umbrella review of meta-analyses. Eur J Epidemiol. (2018) 33:90931. doi: 10.1007/s10654-018-0427-3

37. Neuenschwander M, Ballon A, Weber KS, Norat T, Aune D, Schwingshackl $\mathrm{L}$, et al. Role of diet in type 2 diabetes incidence: umbrella review of meta-analyses of prospective observational studies. BMJ. (2019) 366:12368. doi: $10.1136 /$ bmj.12368
38. Heliövaara M, Aho K, Knekt P, Impivaara O, Reunanen A, Aromaa A. Coffee consumption, rheumatoid factor, and the risk of rheumatoid arthritis. Ann Rheum Dis. (2000) 59:631-5. doi: 10.1136/ard.59.8.631

39. Karlson EW, Mandl LA, Aweh GN, Grodstein F. Coffee consumption and risk of rheumatoid arthritis. Arthritis Rheumat. (2003) 48:305560. doi: 10.1002/art.11306

40. Lamichhane D, Collins C, Constantinescu F, Walitt B, Pettinger M, Parks C, et al. Coffee and tea consumption in relation to risk of rheumatoid arthritis in the women's health initiative observational cohort. J Clin Rheumatol. (2019) 25:127-32. doi: 10.1097/RHU.0000000000000788

41. Mikuls TR, Cerhan JR, Criswell LA, Merlino L, Mudano AS, Burma M, et al. Coffee, tea, and caffeine consumption and risk of rheumatoid arthritis: results from the Iowa Women's Health Study. Arthritis Rheumat. (2002) 46:8391. doi: 10.1002/1529-0131(200201)46:1<83::AID-ART10042>3.0.CO;2-D

42. Pedersen M, Stripp C, Klarlund M, Olsen SF, Tjønneland AM, Frisch M. Diet and risk of rheumatoid arthritis in a prospective cohort. J Rheumatol. (2005) 32:1249-52.

43. Frost-Meyer NJ, Logomarsino JV. Impact of coffee components on inflammatory markers: a review. J Funct Foods. (2012) 4:819-30. doi: 10.1016/j.jff.2012.05.010

44. Schulze MB, Hoffmann K, Manson JE, Willett WC, Meigs JB, Weikert C, et al. Dietary pattern, inflammation, and incidence of type 2 diabetes in women. Am J Clin Nutr. (2005) 82:675-84. doi: 10.1093/ajcn/82.3.675

45. Treloar HR, Piasecki TM, McCarthy DE, Baker TB. Relations among caffeine consumption, smoking, smoking urge, and subjective smoking reinforcement in daily life. J Caffeine Res. (2014) 4:93-9. doi: 10.1089/jcr.2014.0007

46. Hallström H, Wolk A, Glynn A, Michaëlsson K, Byberg L. Coffee consumption and risk of fracture in the Cohort of Swedish Men (COSM). PLoS ONE. (2014) 9:e97770. doi: 10.1371/journal.pone.0097770

47. Chang K, Yang SM, Kim SH, Han KH, Park SJ, Shin JI. Smoking and rheumatoid arthritis. Int J Mol Sci. (2014) 15:2227995. doi: 10.3390/ijms 151222279

48. Daneschvar HL, Smetana GW, Brindamour L, Bain PA, Mukamal KJ. Impact of coffee consumption on physiological markers of cardiovascular risk: a systematic review. Am J Med. (2020) 134:626-36. doi: 10.1016/j.amjmed.2020.09.036

49. Wedick NM, Brennan AM, Sun Q, Hu FB, Mantzoros CS, van Dam RM. Effects of caffeinated and decaffeinated coffee on biological risk factors for type 2 diabetes: a randomized controlled trial. Nutr J. (2011) 10:93. doi: 10.1186/1475-2891-10-93

50. Choi HM, Doss HM, Kim KS. Multifaceted physiological roles of adiponectin in inflammation and diseases. Int J Mol Sci. (2020) 21:1219. doi: 10.3390/ijms21041219

51. Lee YH, Bae SC. Circulating adiponectin and visfatin levels in rheumatoid arthritis and their correlation with disease activity: a meta-analysis. Int $J$ Rheum Dis. (2018) 21:664-72. doi: 10.1111/1756-185X.13038

52. Ramalakshmi K, Raghavan B. Caffeine in coffee: its removal. Why and how? Crit Rev Food Sci Nutr. (1999) 39:441-56. doi: 10.1080/10408699991279231

53. Garabrant DH, Dumas C. Epidemiology of organic solvents and connective tissue disease. Arthritis Res Ther. (1999) 2:5.

54. Górnaś P, Dwiecki K, Siger A, Tomaszewska-Gras J, Michalak M, Polewski K. Contribution of phenolic acids isolated from green and roasted boiled-type coffee brews to total coffee antioxidant capacity. Eur Food Res Technol. (2016) 242:641-53. doi: 10.1007/s00217-015-2572-1

55. Priftis A, Stagos D, Konstantinopoulos K, Tsitsimpikou C, Spandidos DA, Tsatsakis AM, et al. Comparison of antioxidant activity between green and roasted coffee beans using molecular methods. Mol Med Rep. (2015) 12:7293302. doi: $10.3892 / \mathrm{mmr} .2015 .4377$

56. Jin J, Li J, Gan Y, Liu J, Zhao X, Chen J, et al. Tea consumption is associated with decreased disease activity of rheumatoid arthritis in a real-world, largescale study. Ann Nutr Metab. (2020) 76:54-61. doi: 10.1159/000505952

57. Ohishi T, Goto S, Monira P, Isemura M, Nakamura Y. Anti-inflammatory action of green tea. Antiinflamm Antiallergy Agents Med Chem. (2016) 15:7490. doi: 10.2174/1871523015666160915154443

58. Ben Lagha A, Grenier D. Black tea theaflavins attenuate Porphyromonas gingivalis virulence properties, modulate gingival keratinocyte tight junction integrity and exert anti-inflammatory activity. J Periodontal Res. (2017) 52:458-70. doi: 10.1111/jre.12411 
59. Kim HR, Rajaiah R, Wu QL, Satpute SR, Tan MT, Simon JE, et al. Green tea protects rats against autoimmune arthritis by modulating disease-related immune events. J Nutr. (2008) 138:2111-6. doi: 10.3945/jn.108.089912

60. De Maat M, Pijl H, Kluft C, Princen H. Consumption of black and green tea has no effect on inflammation, haemostasis and endothelial markers in smoking healthy individuals. Eur J Clin Nutr. (2000) 54:75763. doi: 10.1038/sj.ejen.1601084

61. Widlansky ME, Duffy SJ, Hamburg NM, Gokce N, Warden BA, Wiseman S, et al. Effects of black tea consumption on plasma catechins and markers of oxidative stress and inflammation in patients with coronary artery disease. Free Radic Biol Med. (2005) 38:499-506. doi: 10.1016/j.freeradbiomed.2004. 11.013

62. Rebello SA, Chen CH, Naidoo N, Xu W, Lee J, Chia KS, et al. Coffee and tea consumption in relation to inflammation and basal glucose metabolism in a multi-ethnic Asian population: a cross-sectional study. Nutr J. (2011) 10:61-. doi: 10.1186/1475-2891-10-61

63. Paiva C, Beserra B, Reis C, Dorea J, Da Costa T, Amato A. Consumption of coffee or caffeine and serum concentration of inflammatory markers: a systematic review. Crit Rev Food Sci Nutr. (2019) 59:652-63. doi: 10.1080/10408398.2017.138 6159

64. Orefice V, Ceccarelli F, Barbati C, Lucchetti R, Olivieri G, Cipriano $\mathrm{E}$, et al. Caffeine intake influences disease activity and clinical phenotype in systemic lupus erythematosus patients. Lupus. (2020) 29:1377-84. doi: 10.1177/0961203320941920
65. Azam S, Hadi N, Khan NU, Hadi SM. Antioxidant and prooxidant properties of caffeine, theobromine and xanthine. Med Sci Monit. (2003) 9:BR325-30.

66. Valdez RC, Ahlawat R, Wills-Karp M, Nathan A, Ezell T, Gauda EB. Correlation between serum caffeine levels and changes in cytokine profile in a cohort of preterm infants. J Pediatr. (2011) 158:57-64. e1. doi: 10.1016/j.jpeds.2010.06.051

Conflict of Interest: The authors declare that the research was conducted in the absence of any commercial or financial relationships that could be construed as a potential conflict of interest.

Publisher's Note: All claims expressed in this article are solely those of the authors and do not necessarily represent those of their affiliated organizations, or those of the publisher, the editors and the reviewers. Any product that may be evaluated in this article, or claim that may be made by its manufacturer, is not guaranteed or endorsed by the publisher.

Copyright (c) 2022 Asoudeh, Dashti, Jayedi, Hemmati, Fadel and Mohammadi. This is an open-access article distributed under the terms of the Creative Commons Attribution License (CC BY). The use, distribution or reproduction in other forums is permitted, provided the original author(s) and the copyright owner(s) are credited and that the original publication in this journal is cited, in accordance with accepted academic practice. No use, distribution or reproduction is permitted which does not comply with these terms. 